Justin Derry

\title{
Incorporeal Encounters and Affective Relationality in Krzysztof Kieslowski's The Double Life of Véronique
}

In Krzysztof Kieslowski's own words, his 1991 film, The Double Life of Véronique, is a "film ... about sensibility, presentiments and relationships that are difficult to name, that are irrational .... [It's about] something that doesn't exist in the picture alone or in the music alone" (Stok 1993: 34). This film, produced in Poland and France, along with his French-produced Three Colours Trilogy of the early 1990s, constitutes the final installment of this Polish-born director's distinguished career. Over his thirty-year career of directing films and documentaries, Kieslowski repeatedly returned to a particular problematic to which most of his work, including The Double Life of Véronique, could be seen as a response. Set within a particular cultural and political history of Europe, Kieslowski's films sought to express a response to the problematic of life, and its paradoxical, immanent and yet differential relationship with death, non-life or what is other than human.

The Double Life of Véronique opens the possibility for a reading of life and the body as being immanently related to a differential field of indeterminate sense and incorporeal potential. Following the philosophical lineage of Spinoza, Bergson, Deleuze and Massumi, the incorporeal can be seen to operate through nonlinear processes from which unexpected and unintended affective events emerge that potentially disrupt causal narrative sequences and autopoietic closed environments. This differential field of incorporeal affect is not abstracted from or transcendent to the systems of meaning characterizing inter-subjective contexts, but is immanent to the processes and experiences an individual lives. Following Massumi, the incorporeal is

never present in position, only ever in passing. This is an abstractness pertaining to the transitional immediacy of a real relation - that of a body to its own indeterminacy (its openness to an elsewhere and otherwise than it is, in any here and now). The charge of indeterminacy carried by a body is inseparable from it. (2002: 5, italics in original)

The Double Life of Véronique can be seen to demonstrate the immanent potential, in the lived and in the actual, of non-human incorporeal forces that exceed the enclosed figures and elements that form to construct a particular subject. Therefore, the force of the incorporeal allows us to think about individuation not only as constructed forms or particular kinds (whether national, gendered or socio-economic), but also as a process that opens the boundaries of a singular life to unexpected connections and new relations. 
Following Claire Colebrook, the Kieslowskian problematic can be read as expressing life as being "at one and the same time a capacity for connection, integration, system and meaning ... and a tendency towards connections that would open the territory [of an individual life] to thresholds that de-form its original system" (2010: 20, italics in the original). In this essay, the corporeal refers to the body's tendency for connective synthesis, which aims to extend and move the formed boundary of an integrated identity through time and space; and the incorporeal refers to the body's other equally important tendency to extend beyond its boundary to an intensive field of sense and affect, opening possibilities and a future that are inconceivable from any enclosed present. Beginning with Freudian psychoanalysis and then moving to current theoretical frameworks dealing with life and the body, it is argued that The Double Life of Véronique can open and expand trajectories of thought that turn on the question of the individuation of the human subject. The focus here will be on theories of the subject and individuation that take into account non-conscious or non-human forces that exceed the sensory-motor circuits figuring human consciousness, yet act by introducing difference and the indeterminate into the systems of meaning constructing the human as a subject. In bringing Freudian psychoanalysis and philosophies of the body and life together the aim is not to demonstrate their distinct opposition, as both convincingly conceptualize the non-conscious forces that exceed the sensory-motor circuit of consciousness. Rather, the aim is to show how contemporary philosophies of the body and life extend through and advance beyond the limits of psychoanalytic theoretical frameworks. In moving away from psychoanalysis - a theoretical framework that tends to focus on repressed unconscious scenes that oppose the conscious ego with negativity, regression and lackphilosophies of the body and life explore the affirmative potential of the incorporeal.

The story of The Double Life of Véronique is broken into two sections dealing with two different characters played by the actress Irène Jacob. One character, Weronika, lives in Poland and the other, Véronique, lives in France. Weronika is depicted as a self-contained individual who narcissistically enjoys the innocent and uninhibited pleasures of a youth unmoved by the threat of death. In the film's second section, Véronique is depicted as an alienated yet more mature woman, driven or compelled by an unknown longing and desire to overcome an unidentifiable sense of isolation or loss. Each character lives her life with no knowledge of the other, yet intuitively they perceive they are related. The first section of the film is devoted solely to the Polish Weronika and ends with her untimely death. Weronika is presented as a sensual, spontaneous, free spirit who after a chance audition is given the lead vocal in a local concert. We learn that Weronika suffers from a heart condition, which she dies from during her performance at the concert. The second section of the film is devoted to Véronique, who appears to be Weronika's double in age, appearance and character. Like Weronika, Véronique is musical, imaginative and sensuous, and to highlight the already apparent uncanny connection the two have, Véronique, a music teacher at an elementary school, teaches her students the same song that Weronika was performing when she died. Kieslowski further intensifies the uncanny connection between the two characters by depicting them as having a warm, caring father, and we learn that the mothers of Weronika and Véronique died when they were both young girls. 
At the school where she teaches, Véronique meets the local author and puppeteer Alexandre with whom she begins a mysterious love affair. Alexandre's sensitive, delicate movements strike Véronique as she watches him maneuver his marionettes. Alexandre notices Véronique's desiring but contented gaze yet leaves the school without speaking with her. From this encounter Véronique identifies Alexandre as the object of her desire and love, and is driven to find the now lost Alexandre in the urban maze that is Paris. In aiding Véronique's search, Alexandre leaves mysterious clues for her spelling out where and how she can find him. Each clue he leaves is doubled by affective, incorporeal resonances that elicit Weronika's uncanny presence. The song Weronika sang when she died is heard in the background, ephemeral images of Weronika at the moment of her death are transposed over scenes of Véronique, and most significantly, Alexandre's marionette puppet performance - the site where Véronique initially began to desire Alexandre - repeats and doubles the story of Weronika's death and Véronique's birth as a mature, fully formed individual. Yet their seemingly destined face-to-face meeting (from Véronique's perspective) is a disappointment, as Alexandre is not who she expected and needed him to be as a love object.

For the most part, the primary problematic of the film hinges on the way Weronika and Véronique are related, questioning whether or not they are one and the same character. Interpretations of the film engaging with psychoanalytic discourses have turned to concepts of doubling, fate and repetition to unpack the film's ambiguous story (Freeland 2004; Knight 2009; Nagler 2003; Zizek 2009). Specifically, Freud's essay The Uncanny (1919) offers a productive entry point into the film's analysis. As Freud describes it, the uncanny is an unpleasant feeling associated with something both strange and familiar. From the conscious-ego, the uncanny can be traced back to repressed infantile complexes or surmounted 'primitive' beliefs which acted as mechanisms to protect the child's gratifying primary narcissistic stage (154-55). What is significant here about the uncanny, understood as the fateful repetition of events and the phenomenon of doubling, is that it attests to the haunting presence of a repressed primary experience that returns to trouble the ego's reality and pleasure principle. For Freud, in the

unconscious mind we can recognize the dominance of a compulsion to repeat, which proceeds from instinctual impulses. This compulsion probably depends on the essential nature of the drives themselves. It is strong enough to override the pleasure principle and lend a demonic character to certain aspects of mental life. (2003b: 144-45, italics in original)

In advancing his understanding of the mechanisms through which the unconscious operates and how non-conscious forces haunt and repeatedly confront the conscious ego, Freud developed a theory of a primary death drive a year later in Beyond the Pleasure Principle (1920). In this essay, Freud fixes the unconscious drive to repeat and return to primary states to a death drive inherent in every living organism (2003a: 76-77). Freud goes on to argue that each individual is driven by two opposed tendencies that don't necessarily correspond to either the pleasure or reality principle, yet compel an individual to repeat or return to a lost primary experience that is 
free from tension (78-79). These opposed drives of life and nonlife "originate in the inner depths of the body" and manifest in the conscious apparatus as energy, force or desire that generate a tension or disequilibrium that the individual unconsciously desires to resolve (74). This unconscious energy provokes a drive to repeat or return the individual to an imagined lost state of equilibrium or an abandoned primary gratification experience that is free from tension. Through this, the compulsion to repeat is infused with an unconscious progressive drive compelling an individual away from tension and toward "higher development" and unattainable perfection, as well as an unconscious, regressive drive aiming to revert a life of disequilibrium back to an inorganic and inanimate state of equilibrium (81-82).

In this sense, the affective presence of Weronika and the marionette dolls that double and haunt Véronique in the second section of the film function to animate Freud's life and death drives, drives that emerge from and attest to an unconscious, repressed "world" beyond the selfconscious ego of the human subject. For Véronique, Weronika's uncanny presence elicits conscious feelings of alienation and unconsciously gestures to a lost state of connection and equilibrium, states broken by the loss of the maternal connection with her mother and the forced withdrawal from the self-contained primary narcissistic state of youth. This initiates a process of transference where Véronique, compelled by the progressive drive to form new relationships that would allow her to unconsciously recreate a lost primary gratifying experience, turns to Alexandre as the object of her desire. Véronique hopes that by bringing Alexandre into her life he will gratify and satisfy her desire for connection as well as bring a sense of equilibrium to her life. Furthermore, opposed to this progressive life drive viewers can intuit the silent working of a regressive death drive figured through Alexandre's inanimate marionette dolls that uncannily double Véronique's looks and experiences. In Véronique's unconscious drive to return to an inanimate state free from tension and disequilibrium she identifies and is moved by nonliving, inorganic dolls.

Looking at the film from a Freudian perspective illuminates a theory of the subject that demonstrates a deeper unconscious world of excess and contingency beyond and before the conscious-ego. According to psychoanalytic theory, these unconscious and nonhuman forces act on consciousness and the human ego to animate particular drives and desires that characterize how we experience, develop and identify the self. Freud develops a framework that works to explain why the individual is always put off balance by forces that seem unreal, irrational and nonhuman. Yet the limitation of this Freudian reading, and the point on which this paper will turn towards contemporary theories of life and the body, is that for Freud these unconscious forces are not initially immanent to life but are negatively opposed to life. Freud's demonstration of the existence of forces beyond and before the self-conscious human ego can take on the negative function of opposition and limitation. The affective presence of Weronika and the marionette dolls that act to double Véronique figure negatively as a lost primary gratification experience, an imaginary scene by which Véronique is forever limited to which she is forever opposed. Regardless of how her identity evolves, and the different forms her identity takes, 
Véronique will be limited and grounded to a primary experience that will direct the drives and desires characterizing her individuality.

Moving away from psychoanalytic discourses and toward philosophies of life and the body, the Kieslowskian problematic of the relation between the human and nonhuman can be seen as opening thought and life to the incorporeal field of the virtual. As described by Massumi, the incorporeal or the

virtual ... is a realm of potential. In potential is where futurity combines, unmediated, with pastness, where outsides are infolded .... The virtual is a lived paradox where what are normally opposites coexist, coalesce, and connect ....

[Yet significantly, the virtual] is inseparable from the concrete activity and expressivity of the body. (2002: 30-31)

The significance of the incorporeal or the virtual tendency of the body is that it opens the potential for singular difference and dynamic emergence within the corporeal. The incorporeal does not add a new or expanded term into the elements constituting identity, but qualitatively mutates the sense of the conditions constituting identity. The incorporeal field of the virtual, which doubles and remains immanent to the corporeal, allows for the emergence of the potential for creative disjunctive evolution of the individual. Significantly, this disjunctive movement of individuation is not from a primary grounding scene or experience, but from the potential to differ in itself.

From this perspective, the Kieslowskian problematic can be seen as an expression of the relation between, on the one hand, the living, repressing, and desiring individual, and on the other, an affective, incorporeal field of potential that is immanent to, but exceeds any enclosed space, time or identity. It expresses the immanent relation between the life of the identifiable individual subject and $a$ singular, impersonal vitalism that is beyond or before good and evil. Borrowing from Massumi, this impersonal, incorporeal vitalism can be described as the "connecting thread of experience. It is the invisible glue that holds the world together. In event ... it is a processual rhythm, in and of the world, expressing ... ongoing qualitative activity (becoming)" (217, italics in the original). One way Kieslowski gestures to this incorporeal, relational field is through repetition. As in psychoanalytic readings, the numerous repeated elements elicit the existence of a differential field beyond the ego and the corporeal, but in extending beyond Freudian psychoanalytic readings - where the repeated elements relate to a primary, grounding experience - these repeated elements can also be seen to bring an opening and qualitative variation into the identity of the same. The sense of the incorporeal opens the possibility for the qualitatively different to mutate the formed elements constituting identity.

In a pivotal scene, Véronique is awoken by a light that she learns is being reflected by a child from a window across the street, yet when the child closes the blinds to the window the light persists. The now sourceless light illuminates the string on her music book. As the sourceless 
light touches the string, the film viewer and Véronique become aware of an immanent nonhuman, affective presence. Throughout the film, string repeatedly becomes the focus of scenes. The string on Weronika's shoe comes undone, Weronika plays with the string on her music book as she auditions for the concert, and the string here acts to advance Véronique's relationship with Alexandre. But though the string itself repeats unchanged across the variations of the Weronika/Véronique series, here the string adds a qualitative, singular difference, or the positivity of an opening, into the seemingly unchanged assemblage of forces constituting Véronique. In this scene, the movement and presence of the incorporeal is intensified as the light, as an unqualified element of sense, becomes not only seen but also heard. With the illumination of the string on the music folder, the tune of the song that Weronika was singing when she died begins to be heard, constituting a rhythmic connection of the senses and the characters. Through this incorporeal force, simultaneously seen as light and heard as melody, Kieslowski elicits the affective relationality between the corporeal and the incorporeal. Furthermore, when Véronique moves to touch and smell the string she not only feels the tactility of the string, but the sensation of touch and smell evokes the sense of an excessive presence, which she attempts to identify by looking through the camera into the open infinitive that is the world outside the film. She becomes aware of the immanence of an excessive, indeterminable presence beyond the threshold of her enclosed, corporeal identity.

The intensive force of the light and string exceeds and therefore cannot be accounted for in a single term, whether in a term of sight, in a term of smell, or in a term of touch. This force is not in anything other than itself, and its potential to differ. Furthermore, in her look beyond the threshold of her corporeal identity, does Véronique perceive an imagined primary scene opposed to her present? Or does she sense the force and potential of difference itself, given in the infinite number of worlds, infinite differences and infinite potentials constituting the lives of the viewers watching her from outside the film (which could be multiplied again as the film viewers, through Véronique's gaze, sense another infinite number of worlds, infinite differences and infinite potentials through the lives of their fellow film viewers)? This light that evokes a sound, and this touch and smell that open the present to an indeterminate infinitive constitute an event of opening in the corporeal identity of Véronique. This indeterminate opening mobilizes a series of determined actions advancing her relationship with Alexandre. In the previous scene he had left her a piece of string as a clue to his whereabouts, and in the following scene Véronique decides to return to the discarded string, initiating her interest in locating the owner. This scene demonstrates the potential of the body to sense connections that exceed the bounded organs' synthetic range, opening the potential for an event of becoming that qualitatively mutated her embodied identity (i.e. she decided to pursue her mysterious suitor). This excessive presence can be seen as an opening to an unexpected and indeterminate future.

When Kieslowski states that "there's no action in the film" he implies that the film is gesturing to that part of life and reality that the intellect cannot enclose in perception, but can only experience as an unformed intuition (Stok 1993: 56). Kieslowski can be seen to be gesturing 
towards a positive field of incorporeal force and affect that acts to open thought and relate the body to un-lived future potentials, a future of indeterminate dynamic emergence. Today, in thinking about life and the body, it is imperative to look beyond those models where identity, the body, the organism or the system find their driving, animating force only within themselves, and therefore close off life and the body to the affective, non-human intensive forces of the incorporeal. Under such models, the self and the world constituted as a reflection of that self easily fall into a narcissistic, self-enclosed coupling, and as Freud rightly warns, this tends toward neurosis and dissolution.

Life can't be reduced to the life of a particular living being, as life and the human are always open to non-human forces that continually challenge us, not to expand the conception of the human, but to re-figure what life and the human mean. As Deleuze notes, the acting, corporeal individual has "to enter into relations with yet other forces, so that it could itself escape from a world of clichés. It had to open up to powerful and direct revelations" which put the unthought into thought (1989: 23). By extending the eye beyond what it can see, and the ear beyond what it can hear, a living being opens to a world of image and noise that can positively contribute to processes of dynamic emergence and singular difference. To do so is to confront the forces of the future. To open the necessarily constituted boundary of identity to a world of sense beyond any enclosed identity, and to become other than what one is, is to confront not this or that particular future, but the infinite indeterminate power of the future as such.

\section{References}

Colebrook, Claire. 2000. Incorporeality: The Ghostly Body of Metaphysics. Body \&Society 6(2): 25-44. 2010. Deleuze and the Meaning of Life. New York: Continuum International Publishing Group. Deleuze, Gilles. 1989. Cinema 2: The Time-Image. Minneapolis: University of Minnesota Press. 1994. Difference and Repetition. New York: Columbia University Press.

Freeland, Cynthia. 2004. Explaining the Uncanny in The Double Life of Véronique. In Horror Film and Psychoanalysis: Freud's Worst Nightmare, edited by Steven Jay Schneider, 87-105. New York: Cambridge University Press.

Freud, Sigmund. 2003a. Beyond the Pleasure Principle and Other Writings. New York: Penguin Books. 2003b. The Uncanny. New York: Penguin Books.

Knight, Christopher J. 2009. "For Once, Then, Something”: Krzysztof Kieslouski's The Double Life of Veranique and the apophatic beyond. Literature/Film Quarterly 37(4): 283-294.

Massumi, Brian. 2002. Parables for the Virtual: Movement, Affect, Sensation. Durham: Duke University Press.

Nagler, Lihi. 2003. Singling Out the Double: Objectivity, Subjectivity and Alterity in Kieslowski's The Double Life of Veronique. Post Script: Essays in Film and the Humanities 22(3): 8-14. 
Incorporeal Encounters and Affective Relationality in Krzysztof Kieslowski’s The Double Life of Véronique | Justin Derry

Stok, Danusia. 1993 Kieslowski on Kieslowski. London: Faber and Faber.

Zizek, Slavoj. 2001. The Fright of Real Tears: Krzysztof Kieslowski between Theory and Post-Theory. London: British Film Institute. 